\title{
The peripheral soft tissues should not be ignored in the finite element models of the human knee joint
}

\author{
Hamid Naghibi Beidokhti ${ }^{1}$ (I) $\cdot$ Dennis Janssen ${ }^{1} \cdot$ Sebastiaan van de Groes ${ }^{2} \cdot$ Nico Verdonschot $^{1,3}$
}

Received: 2 February 2017 / Accepted: 20 November 2017 / Published online: 7 December 2017

(C) The Author(s) 2017. This article is an open access publication

\begin{abstract}
In finite element models of the either implanted or intact human knee joint, soft tissue structures like tendons and ligaments are being incorporated, but usually skin, peripheral knee soft tissues, and the posterior capsule are ignored and assumed to be of minor influence on knee joint biomechanics. It is, however, unknown how these peripheral structures influence the biomechanical response of the knee. In this study, the aim was to assess the significance of the peripheral soft tissues and posterior capsule on the kinematics and laxities of human knee joint, based on experimental tests on three human cadaveric specimens. Despite the high inter-subject variability of the results, it was demonstrated that the target tissues have a considerable influence on posterior translational and internal and valgus rotational laxities of lax knees under flexion. Consequently, ignoring these tissues from computational models may alter the knee joint biomechanics.
\end{abstract}

Keywords Finite element method $\cdot$ Knee laxity $\cdot$ Knee peripheral tissues $\cdot$ Knee posterior capsule $\cdot$ Kinematics

\section{Introduction}

The finite element (FE) method is being widely utilized as a research tool to investigate knee biomechanics [1]. However, every FE model of either native or implanted knees suffers from limitations and simplifications [2]. In even the most comprehensive FE model of the knee, soft tissue structures like tendons and ligaments are being incorporated, but usually skin, peripheral soft tissues, and the posterior capsule are ignored, mostly due to the lack of experimental data on their influence on the joint kinematics and laxity [3, 4] (Fig. 1). On the other hand, only a few studies modeled posterior capsule in either native (i.e.,

Hamid Naghibi Beidokhti

Hamid.NaghibiBeidokhti@radboudumc.nl

1 Orthopedic Research Laboratory, Radboud Institute for Health Sciences, Radboud University Medical Center, 6525

GA Nijmegen, The Netherlands

2 Orthopaedic Department, Radboud University Medical Center, Nijmegen, The Netherlands

3 Laboratory of Biomechanical Engineering, University of Twente, Enschede, The Netherlands
Shin et al. [5]) or implanted (i.e., Baldwin et al. [6]) knee models, roughly approximating the properties based on the limited experimental data of Brantigan and Voshell [7] (Fig. 1c). The influence of these peripheral structures on the biomechanical behavior of the knee joint is largely unknown and usually assumed to be of minor influence on the overall kinematics of the knee joint.

Geiger et al. reviewed the posterolateral and posteromedial soft tissue structures [8]. LaPrade et al. verified the quantitative anatomy of medial structures of the knee joint including the posterior oblique ligament [9]. None of them, however, assessed the properties of their target tissues. A few studies investigated the effect of the lateral soft tissues, and more importantly of the popliteofibular ligament and popliteal tendon, on varus and external rotational laxities under limited loading conditions [10-13]. Their results indicated that the popliteofibular ligament contributes to posterolateral stability [12] and prevents excessive posterior translation and varus angulation [11], especially when the knee is flexed [13]. Sugita et al. indicated that the popliteal tendon and popliteofibular ligaments are equally important in posterolateral stability of the knee [10]. Griffith et al. measured the oblique popliteal ligament (OPL) force at different loading conditions and indicated that it takes part in the internal and 
a

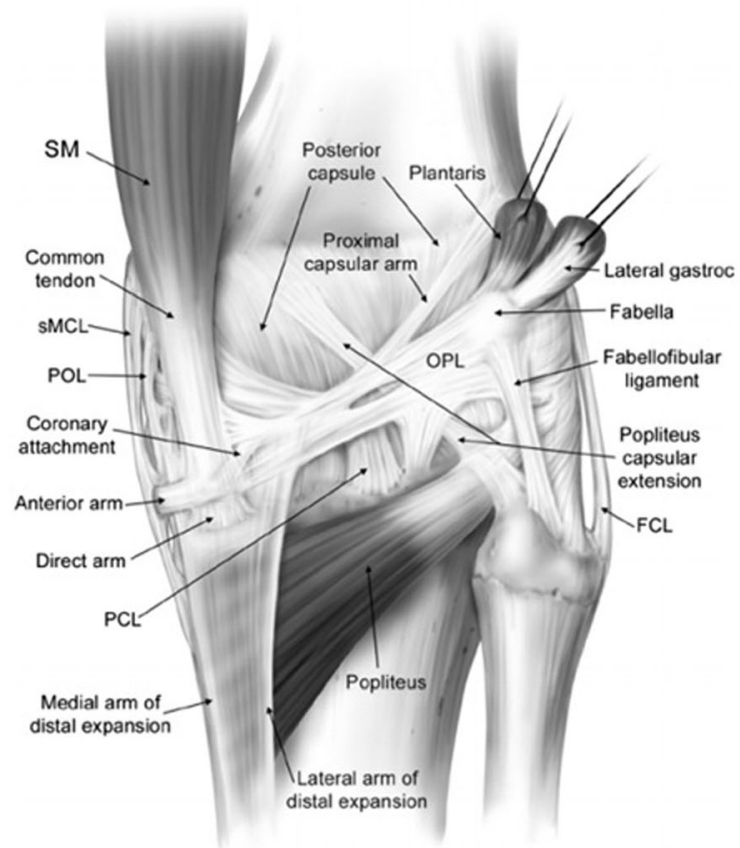

b

C

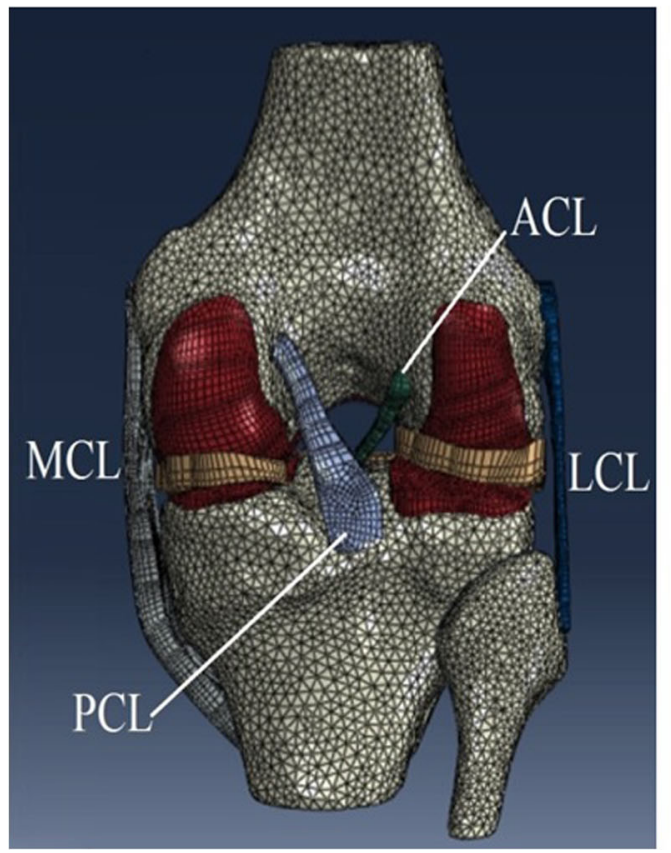

Fig. 1 A posterior view of a schematic human knee joint (reproduced from [8] Elsevier license permission 3932521102554) (a); a typical FE model of a native knee joint (reused from [14], the original image was
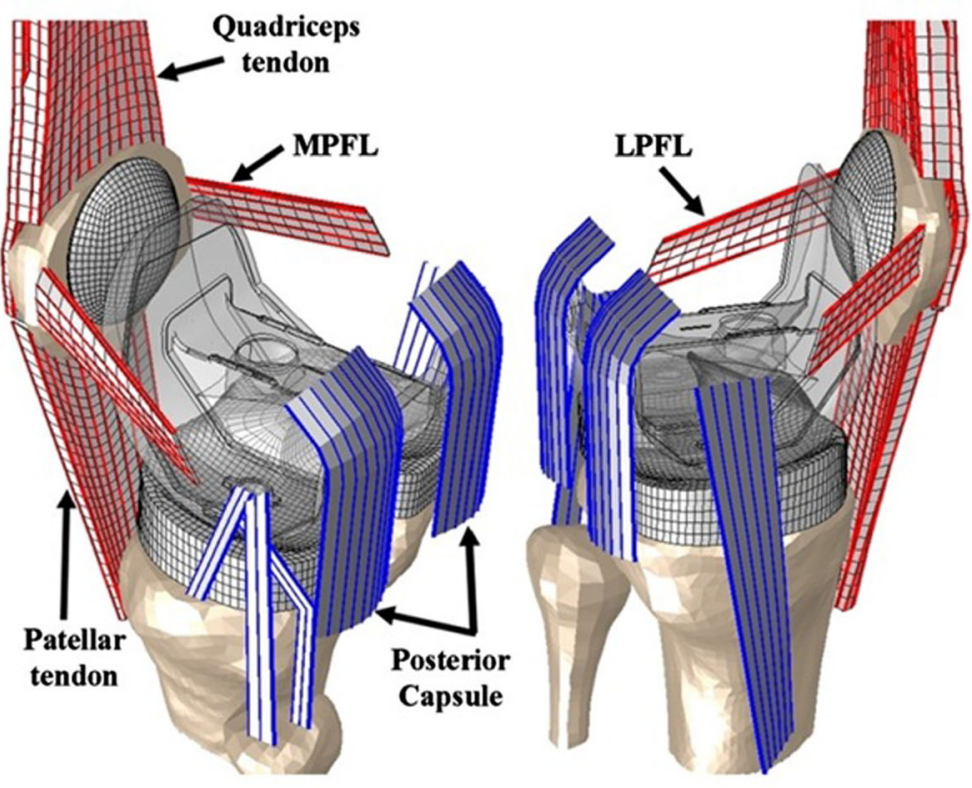

horizontally flipped and labeled) (b); and an FE model with posterior capsule inclusion (reproduced from [6] Elsevier license permission 3981261251500) (c)

The influence of the peripheral structures and posterior capsule on knee joint laxity has not been completely described in the literature, but is of interest for computational modelers. The aim of this study, therefore, was to assess the significance of the peripheral soft tissues and posterior capsule on the kinematics and laxity of the human knee joint. Accordingly, a computational approach to model the target tissues in FE was sought. 
Fig. 2 The six-DOF knee testing apparatus (a); a single knee joint positioned in the testing apparatus with the tracking sensors attached to bony segments: pre-dissection joint (b) and post-dissection joint (c)

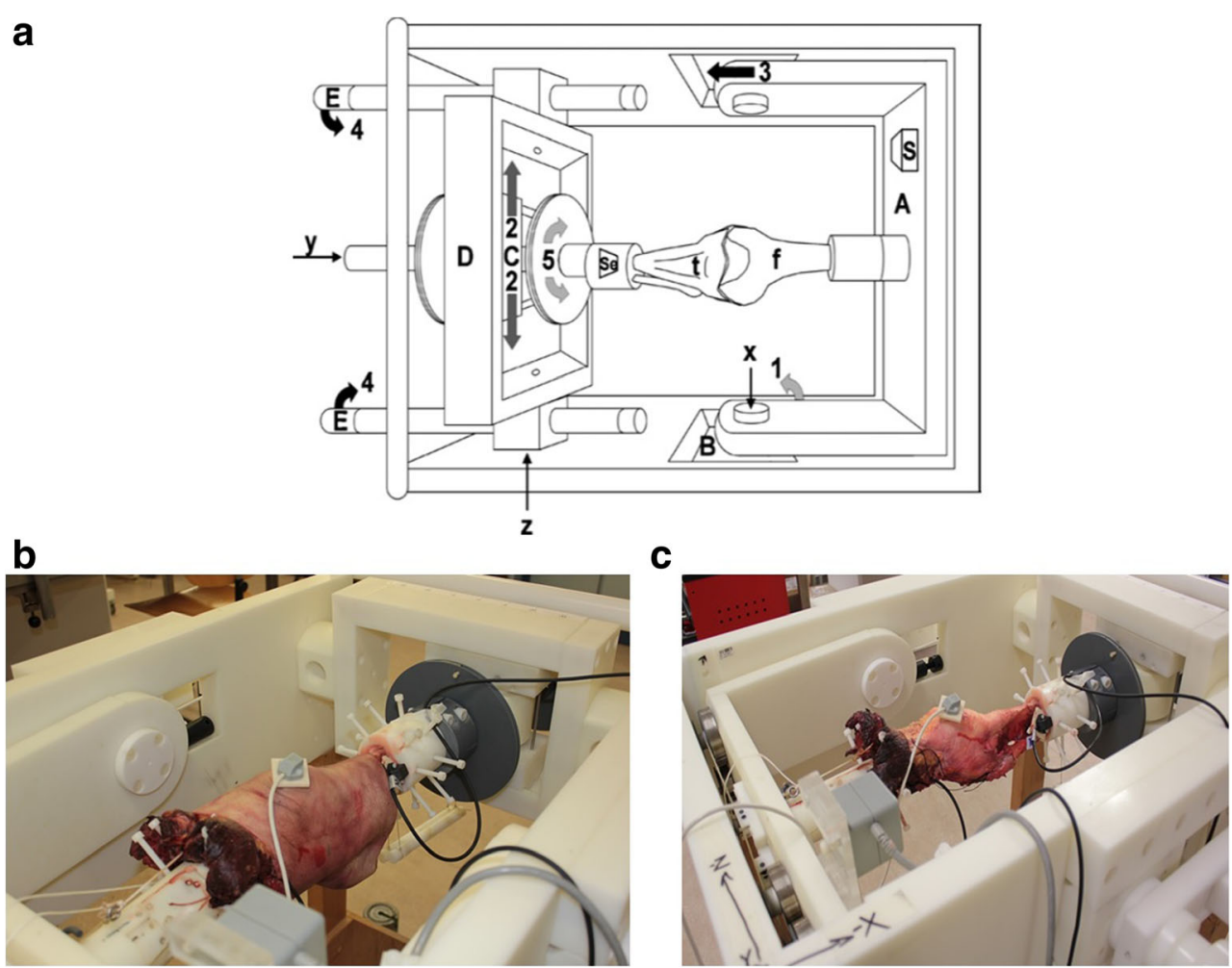

\section{Materials and methods}

\subsection{Experimental testing}

Three fresh-frozen cadavers with a mean age of $79 \pm 21$ years, with no signs of hard and soft tissues injuries and no history of surgery were selected for the current study. The specimens were received from the Anatomy Department of Radboud University Medical Center with a permission statement for experimental use. The knees were prepared following a standard protocol and positioned in a knee testing apparatus that allows for six degree of freedom motions (Fig. 2a) [17-19].
Flexion-extension was applied to the femur, whereas the valgus-varus and internal-external rotations and anteriorposterior and medial-lateral translations were applied to the tibia.

The quadriceps muscles were subjected to constant forces provided by torsional springs representing the vastus lateralis $(20 \mathrm{~N})$, rectus femoris $(20 \mathrm{~N})$, and the grouped vastus medialis and intermedius $(10 \mathrm{~N})[17,20,21]$. These loads were selected based on the force magnitude limitations of the knee testing apparatus and applied in order to stabilize the patella and, as a result, were not meant to be representative of quadriceps loads during in vivo tasks.
Fig. 3 The validated subjectspecific FE models of the three cadaveric knees $(\mathrm{C} 1, \mathrm{C} 2$, and $\mathrm{C} 3)$ with five springs added to be representative for the dissected tissues as oblique popliteal ligament (OPL), arcuate popliteal ligament (APL), medial capsule (MCap), lateral capsule (LCap), and anterolateral ligament (ALL)

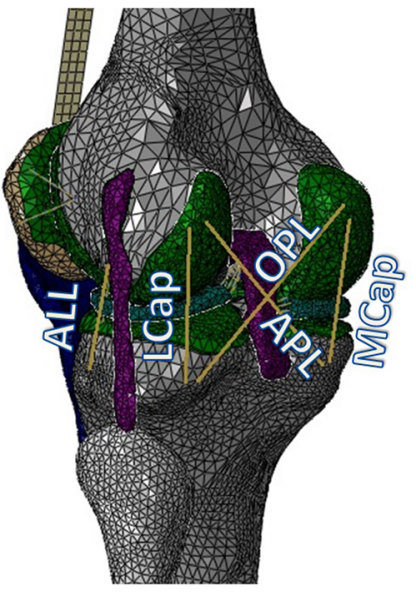

C1

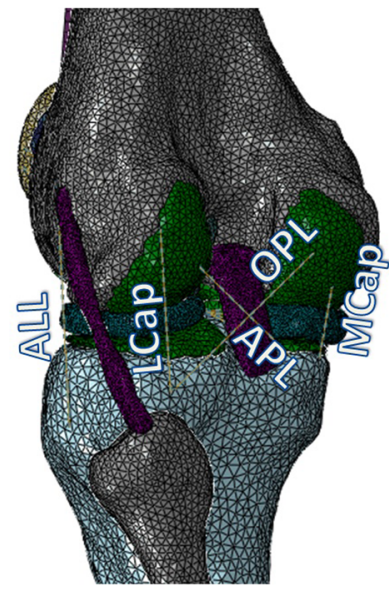

C2

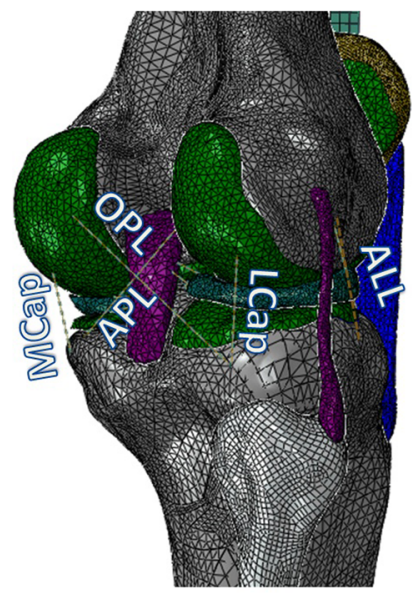

C3 
Table 1 Average laxity changes in the six loading conditions following the dissection $( \pm$ standard deviations) for all three specimens

\begin{tabular}{|c|c|c|c|c|c|c|c|}
\hline & & \multicolumn{6}{|c|}{ Loading regimes } \\
\hline & & $\begin{array}{l}\text { Internal } \\
\text { torque } \\
(5.16 \mathrm{Nm}) \\
\text { Internal } \\
\text { rotation }\left(^{\circ}\right)\end{array}$ & $\begin{array}{l}\text { External } \\
\text { torque } \\
(5.16 \mathrm{Nm}) \\
\text { External } \\
\text { rotation }\left(^{\circ}\right)\end{array}$ & $\begin{array}{l}\text { Varus } \\
\text { moment } \\
(12 \mathrm{Nm}) \\
\text { Varus } \\
\text { rotation }\left(^{\circ}\right)\end{array}$ & $\begin{array}{l}\text { Valgus } \\
\text { moment } \\
(12 \mathrm{Nm}) \\
\text { Valgus } \\
\text { rotation }\left(^{\circ}\right)\end{array}$ & $\begin{array}{l}\text { Anterior } \\
\text { load } \\
(100 \mathrm{~N}) \\
\text { Anterior } \\
\text { translation } \\
(\mathrm{mm})\end{array}$ & $\begin{array}{l}\text { Posterior } \\
\text { load } \\
(100 \mathrm{~N}) \\
\text { Posterior } \\
\text { translation } \\
(\mathrm{mm})\end{array}$ \\
\hline \multirow{4}{*}{$\begin{array}{c}\text { Flexion } \\
\text { angle } \\
\left(^{\circ}\right)\end{array}$} & 0 & $0.5 \pm 0.6$ & $0.5 \pm 0.2$ & $0.3 \pm 1.0$ & $0.5 \pm 0.8$ & $0.0 \pm 0.8$ & $0.2 \pm 1.3$ \\
\hline & 30 & $1.5 \pm 0.8$ & $0.2 \pm 0.8$ & $0.2 \pm 1.0$ & $0.9 \pm 1.2$ & $0.1 \pm 0.5$ & $0.1 \pm 1.8$ \\
\hline & 60 & $6.0 \pm 1.4$ & $1.1 \pm 1.7$ & $0.0 \pm 0.3$ & $0.3 \pm 1.2$ & $0.3 \pm 0.4$ & $0.1 \pm 0.8$ \\
\hline & 90 & $6.3 \pm 3.5$ & $0.9 \pm 2.1$ & $0.1 \pm 0.6$ & $0.3 \pm 1.7$ & $0.2 \pm 0.6$ & $0.4 \pm 0.8$ \\
\hline
\end{tabular}

An electromagnetic tracking system (3Space Fastrak, Polhemus Incorporated, VT, USA) was used to track sensors that were rigidly attached to the femur, tibia, and patella, using base plates screwed onto the bone. Subsequently, the knees with the base plates in situ were CT scanned (Toshiba Aquilion ONE, Otawara, Japan) with a slice thickness of $0.5 \mathrm{~mm}$ and segmented using Mimics v18.0 (Materialise, Leuven, Belgium). The segmented three-dimensional models were used to determine the relative position and orientation of sensors with respect to the joint. In-house developed scripts (MATLAB R2013a, Natick, MA) were used to calculate the knee joint center (similar to [22]) and to convert the raw tracking data to kinematics in the knee joint coordinate system [23], as described by Grood and Suntay [24].

Six different loading conditions were applied to the intact knees (Fig. 2b) at four different flexion angles $\left(0^{\circ}, 30^{\circ}, 60^{\circ}\right.$, and $90^{\circ}$ ): internal and external torque of $5.16 \mathrm{Nm}$, a varus and valgus moment of $12 \mathrm{Nm}$, and an anterior and posterior load of $100 \mathrm{~N}$. These loads were based on the literature values and can provide sufficient laxity motion to characterize the knee ligamentous structures without damaging the cadaveric specimens [6, 24-27]. The loads were applied within the physiological loading range $(\sim 1 \mathrm{~s})$. The measurements were performed after $\sim 3 \mathrm{~s}$ of external loading, and after which, the biomechanical response of the ligamentous structures of the knee joint would not considerably be influenced by the tissue viscoelasticity [28].

Subsequently, the knee joints were dissected by an experienced knee surgeon to remove the skin, peripheral soft tissues and posterior capsule, while preserving the salient tibiofemoral ligaments such as the anterior and posterior cruciate ligaments, and the medial and lateral collateral ligaments (Fig. 2c). Subsequently, the loading conditions as described above were repeated to determine the effect of the dissection
Fig. 4 Anterior-posterior laxity of the three cadaveric knees at four flexion angles indicating unloaded (middle square), anteriorly loaded (upward bars), and posteriorly loaded (downward bars) cases

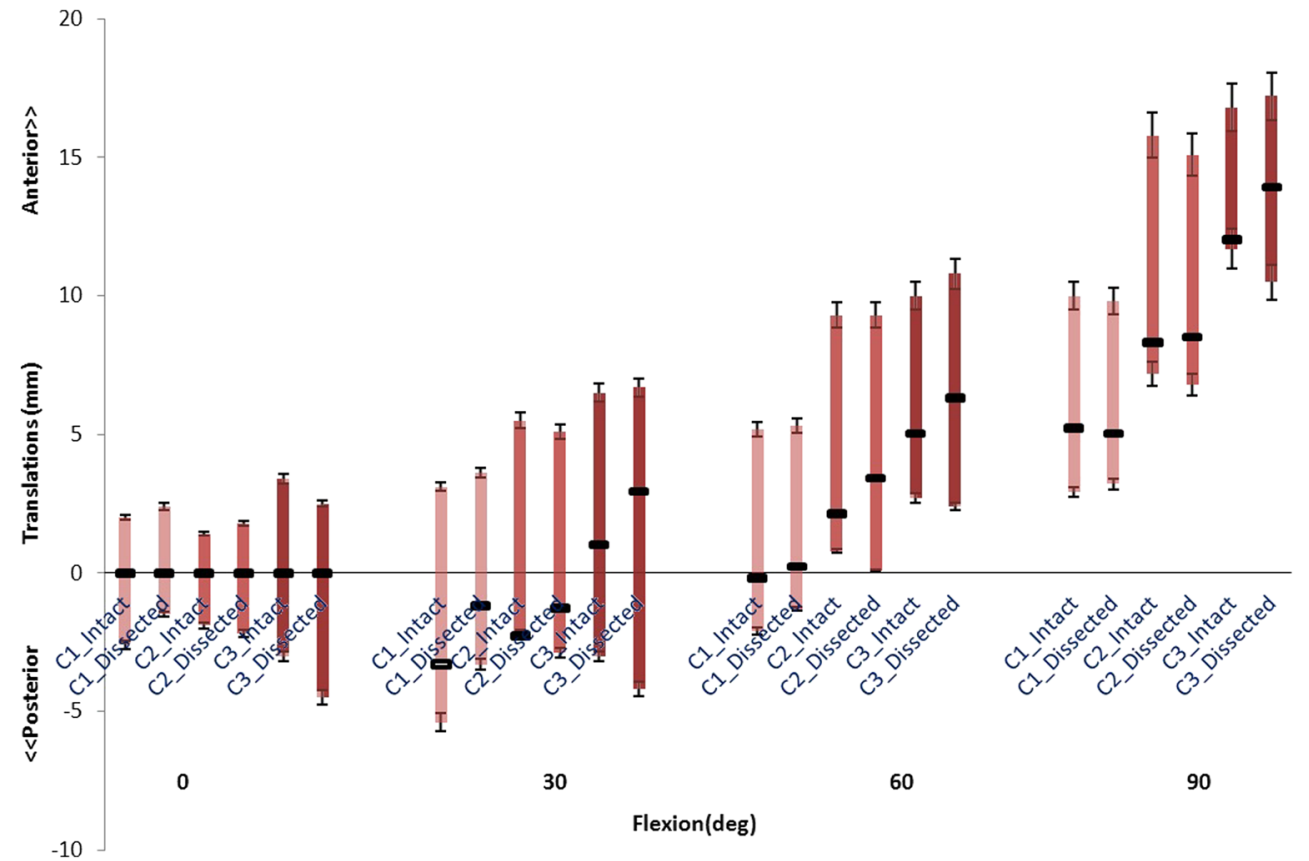


Fig. 5 Internal-external rotations of three cadaveric knees at four flexion angles indicating unloaded joints (middle square), and with internal torque (upward bars) and external torque (downward bars)

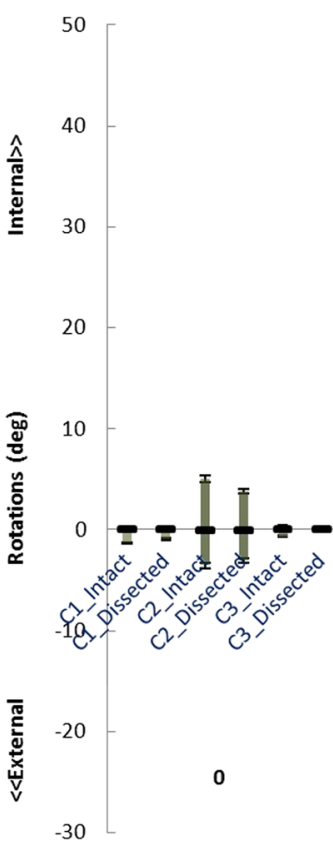

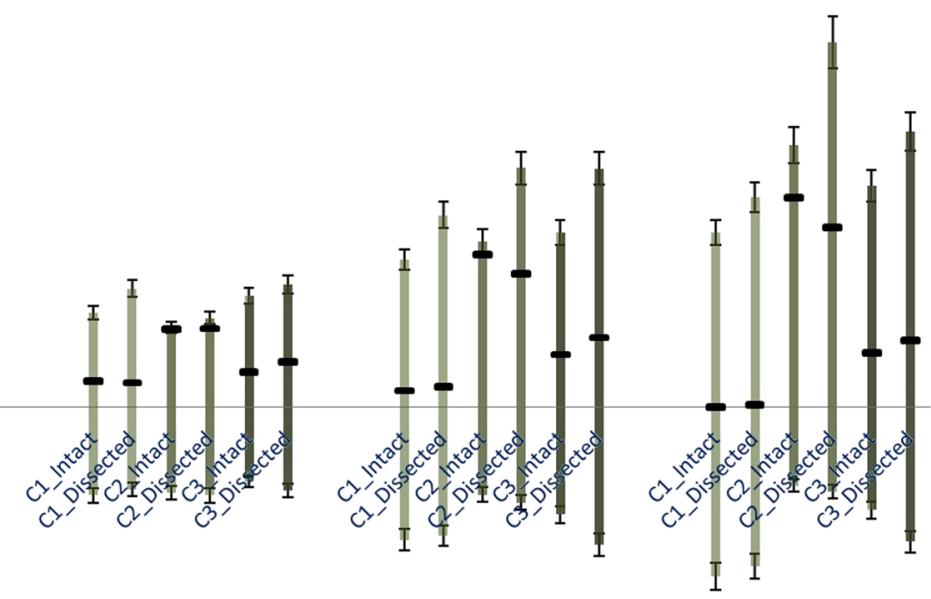

30

90 of the peripheral soft tissue structures. Each of the loading conditions was repeated three times to check the repeatability of the measurements, and their mean and standard deviation were calculated.

\subsection{Finite element modeling}

Three validated subject-specific FE models of the three dissected knees were developed in our earlier study [29]. Five structures were added to each FE model, including oblique popliteal ligament (OPL), arcuate popliteal ligament
(APL), medial capsule (MCap), lateral capsule (LCap), and anterolateral ligament (ALL) (Fig. 3). The insertion sites were estimated from the segmented model and anatomy textbooks. All the structures were modeled as nocompression linear spring, and the initial stiffness was assigned from the literature [10, 11, 13, 29-32]. The stiffness of each structure was varied within the specified range to obtain the closest laxity prediction to the experimentally measured laxity in the intact knee, under the six loading regimes described previously. The same approach was previously used by Baldwin et al. [6].
Fig. 6 Varus-valgus rotations of three cadaveric knees at four flexion angles indicating unloaded joints (middle square), and with varus moment (upward bars) and valgus moment (downward bars)

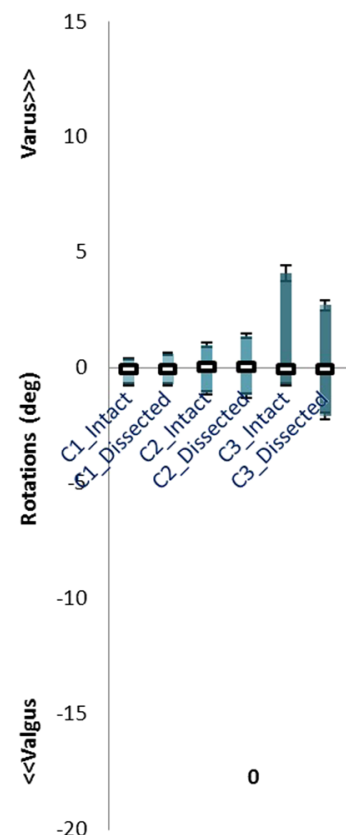

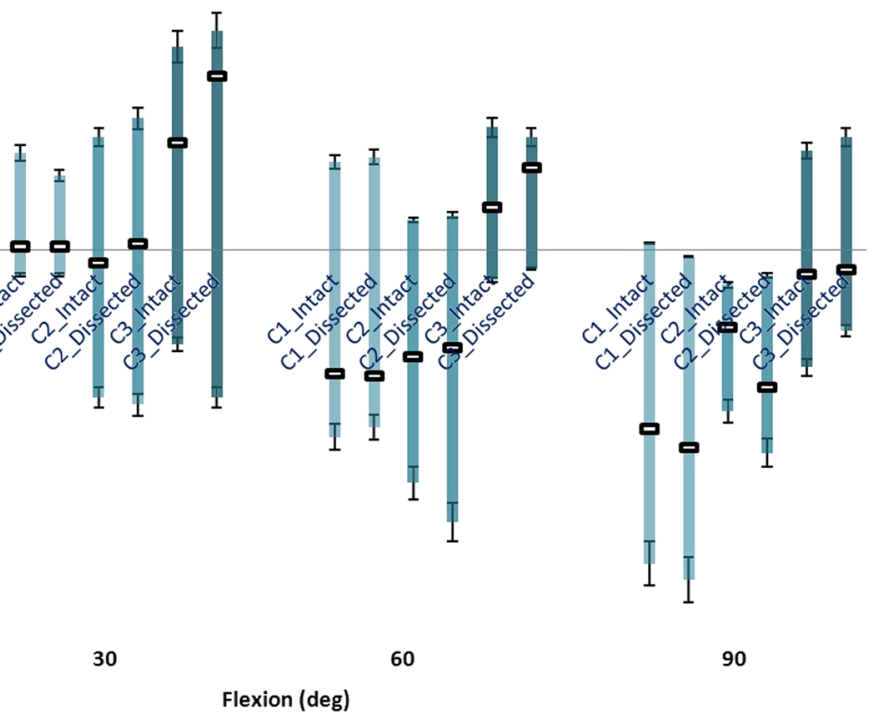


Table 2 The spring stiffness of the five modeled structures to be representative for the dissected structures, in three subject-specific FE models

The stiffness of the representative spring elements $(\mathrm{N} / \mathrm{mm})$

\begin{tabular}{llllll}
\cline { 2 - 6 } & APL & OPL & ALL & MCap & LCap \\
\hline Initial value \pm range & $28 \pm 14$ & $28 \pm 14$ & $42 \pm 26$ & $15 \pm 10$ & $15 \pm 10$ \\
C1 & 34 & 25 & 40 & 15 & 14 \\
C2 & 40 & 30 & 45 & 19 & 17 \\
C3 & 32 & 42 & 42 & 23 & 15 \\
\hline
\end{tabular}

\section{Results}

In the following, the laxity outcomes of the specimens pre- and post-dissections were compared separately for anterior- posterior translational, internal-external rotational, and valgusvarus rotational laxities. Despite the large inter-subject variability in some directions, the average laxity changes following dissection ( \pm standard deviations) of the three specimens have been included in Table 1. Subsequently, the peripheral soft tissue stiffness values were incorporated in the FE models. Finally, the FE laxity predictions with and without these additional structures were compared with the experimental measurement.

\subsection{Experimental laxities}

Anterior-posterior laxity Figure 4 shows the anterior-posterior laxity in the three specimens, for the pre- and post-dissection cases.

All dissected knees showed a slightly larger average tibial anterior translation ( 1.0 to $2.1 \mathrm{~mm}$ at $30^{\circ}$ and 0.4 to $1.3 \mathrm{~mm}$ at $60^{\circ}$ ). At $90^{\circ}$, the first two knees were negligibly affected by
Fig. 7 The anterior-posterior laxity predicted by FE models with (intact) and without (dissected) additional spring structures and measured in the experiment at different flexion angles

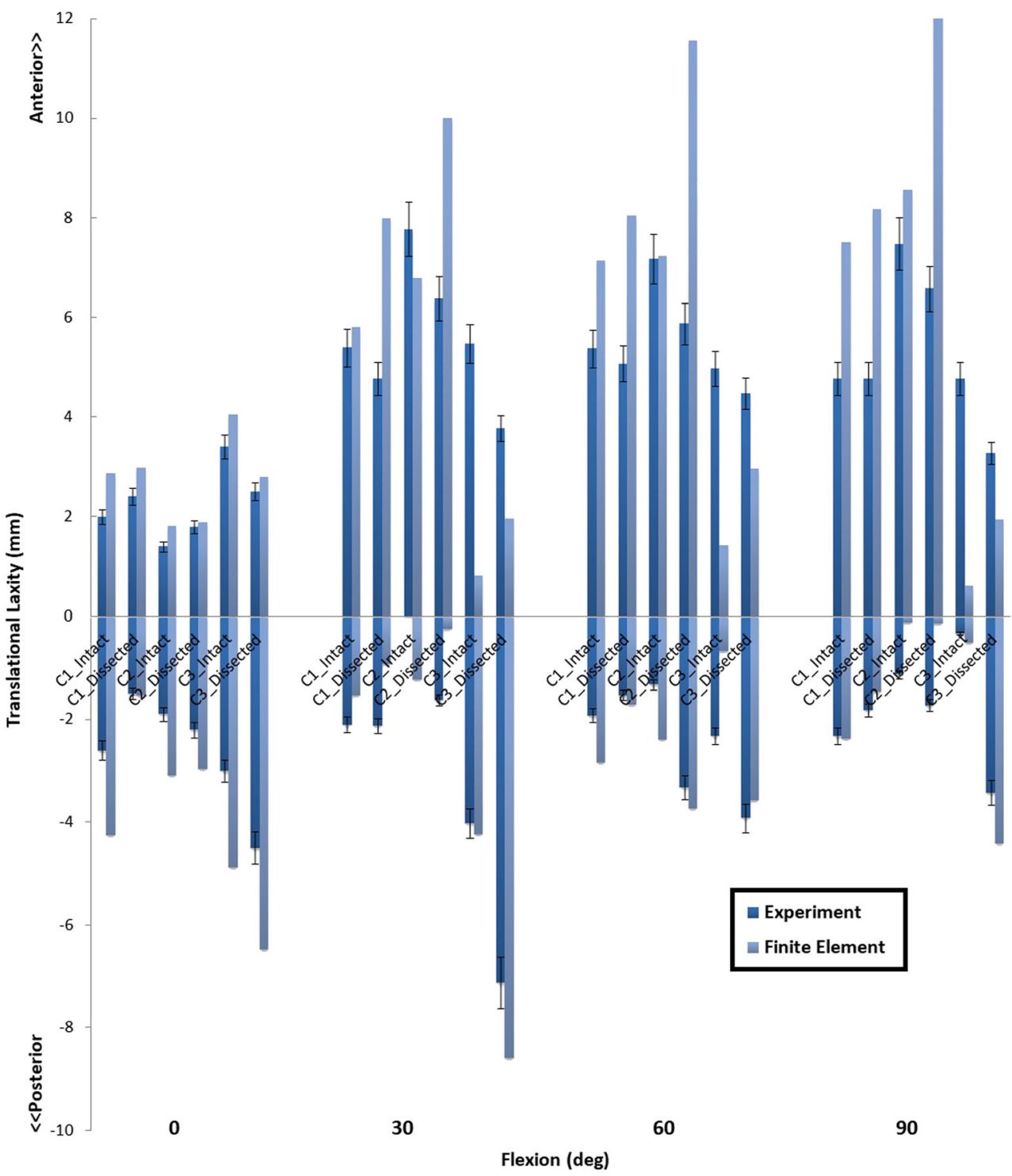


the dissection of the peripheral tissues, while the difference in the third knee was $1.9 \mathrm{~mm}$. No considerable difference in anterior translation was found between the three knees.

Surprisingly, the posterior laxity of the first knee was reduced after dissection, although by less than $1.0 \mathrm{~mm}$. In the second specimen, the posterior laxity increased by 1.7 and $1.0 \mathrm{~mm}$ at $30^{\circ}$ and $60^{\circ}$, respectively. The third knee was more sensitive to peripheral soft tissues, as the posterior laxity at $0^{\circ}$, $30^{\circ}, 60^{\circ}$, and $90^{\circ}$ increased by $1.5,3.1,1.6$, and $3.1 \mathrm{~mm}$, respectively.

Internal-external laxity Internal-external rotations of the first and third specimens were negligibly influenced by dissection during flexion, whereas the second specimen maximally showed an external rotational perturbation of $2.9^{\circ}$ at $90^{\circ}$ (Fig. 5).

Internal rotation increased by less than $1.2^{\circ}$ after peripheral soft tissue removal for all specimens at full extension and $30^{\circ}$ of flexion, except for the first knee $\left(2.6^{\circ}\right.$ increase at $\left.30^{\circ}\right)$. At larger flexion angles, the laxity increased up to $12.9^{\circ}$.

Upon application of external rotation, the rotation of the first and second knees increased maximally by $1.7^{\circ}$ after dissection, where in the third specimen, its rotations increased up to $5.7^{\circ}$ at $60^{\circ}$ flexion and $4.4^{\circ}$ at $90^{\circ}$ flexion.
Valgus-varus laxity In unloaded flexion, the first specimen showed only a slight valgus rotational increase at $90^{\circ}$ by about $1.0^{\circ}$ (Fig. 6). The second and third knees were inclined to more varus rotation at $30^{\circ}$ and $60^{\circ}$ of flexion, by less than $1.0^{\circ}$ for the second knee and $2.9^{\circ}\left(30^{\circ}\right.$ flexion $)$ and $1.7^{\circ}\left(60^{\circ}\right.$ flexion) for the third specimen. In $90^{\circ}$ of flexion, only the second knee was considerably influenced by soft tissue removal (5.0 $0^{\circ}$ valgus).

Upon applying a varus moment, the maximum increase in varus rotational laxity occurred at $90^{\circ}$ of flexion for the second specimen $\left(3.0^{\circ}\right)$, where for the first and third knees, it was less than $1.0^{\circ}$ in all flexion angles.

\subsection{Finite element models}

Table 2 shows the estimated stiffness for the modeled structures (APL, OPL, ALL, MCap, and LCap), with which the closest intact knee laxity was obtained for all three knee specimens. The laxity outcomes for FE models with and without the additional structures were compared with the experimental laxity results in Fig. 7 (anterior-posterior), Fig. 8 (internalexternal), and Fig. 9 (valgus-varus).
Fig. 8 The internal-external rotational laxity predicted by $\mathrm{FE}$ models with (intact) and without (dissected) additional spring structures and measured in the experiment at different flexion angles

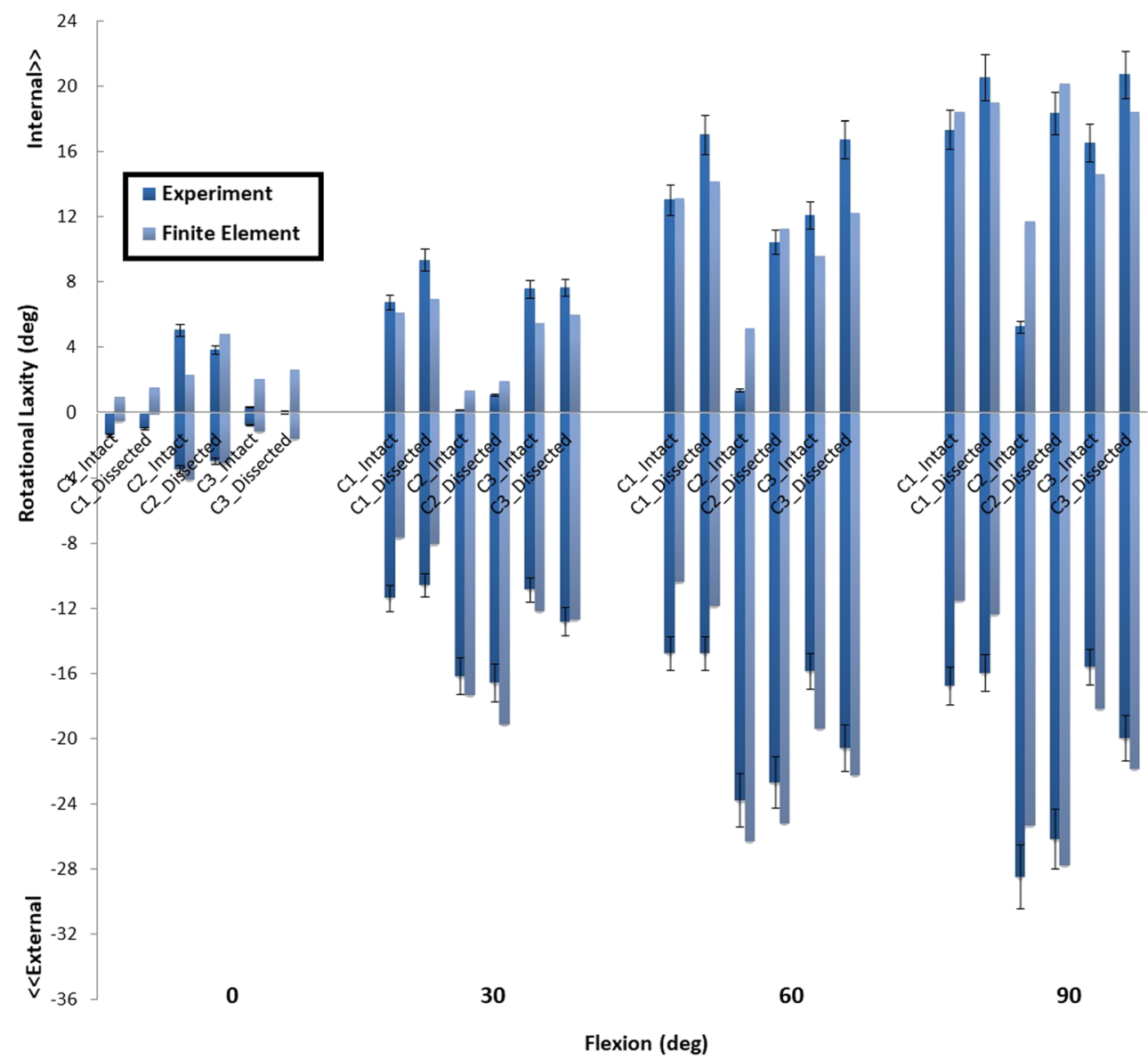


Fig. 9 The valgus-varus rotational laxity predicted by $\mathrm{FE}$ models with (intact) and without (dissected) additional spring structures and measured in the experiment at different flexion angles

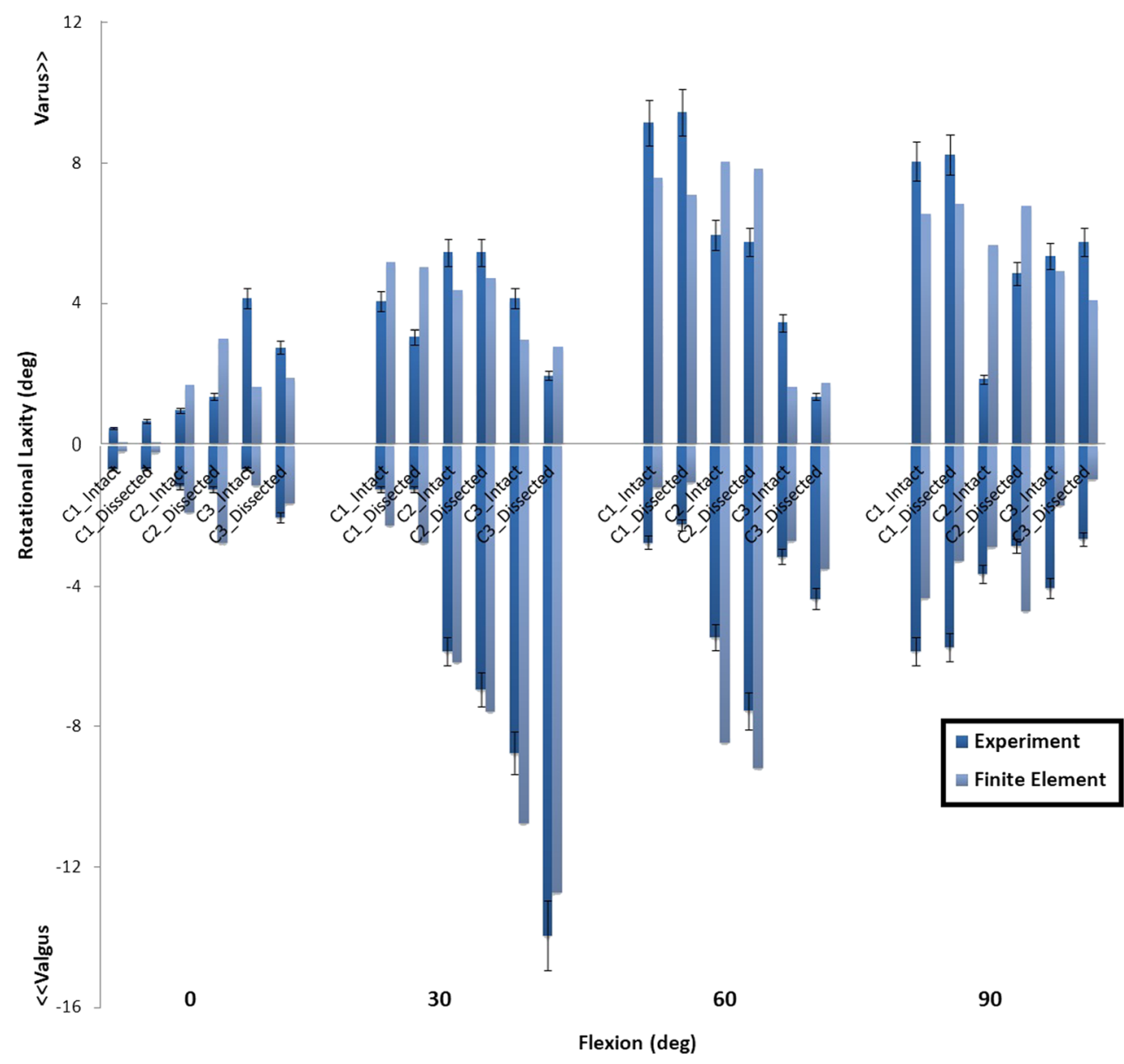

\section{Discussion}

In the current study, the influence of the peripheral soft tissues and posterior capsule on knee joint laxity was investigated based on laxity tests in three human cadaveric specimens. Six different loading regimes were applied to each specimen pre- and post-dissection, at four different flexion angles. Based on the laxity outcomes, additional structures were modeled in three validated specimen-specific FE models to achieve the pre-dissection knee laxities.

Removal of the peripheral soft tissues only had a limited effect on the anterior-posterior laxity, but it did effect the neutral (unloaded) position of the joint. At larger flexion angles, the peripheral tissue provided substantial internal rotational constraints, but it did not change the neutral rotational position in an unloaded state. In lax knees, the peripheral tissues showed a limited influence on neutral valgus-varus rotations and valgus rotational laxity.

The implication of omission of the peripheral and posterior capsular tissue in knee models can therefore vary depending on the simulated task and the loading conditions. Werner et al. showed that contact distribution and contact loads on medial and tibial compartments significantly changed with a valgus- varus variation as little as $3^{\circ}$ in gait, based on the experiment on four cadaveric implanted knees [33]. Similar findings of Engin et al. on human native knee joint confirm the high sensitivity of knee contact biomechanics to valgus-varus rotational configurations [34].

Our results indicate a valgus-varus change beyond $3^{\circ}$ at flexion angles of $60^{\circ}$ and $90^{\circ}$ with peripheral tissues and posterior capsule removal. The change in internal-external laxity by ignoring the peripheral tissues can alter not only tibiofemoral joint behavior but also the biomechanics of patellofemoral joint. However, patellar kinematics and patellofemoral contact pressure were shown to be slightly more sensitive to internal rotation, where an internal rotational change of $5^{\circ}$ can alter the patellofemoral joint biomechanical behavior [35]. The alteration in the posteriorly directed joint behavior by ignoring peripheral and capsular tissues can also lead to different cruciate ligament forces $[5,36]$. According to Yao et al., an anteriorposterior perturbation of even $0.1 \mathrm{~mm}$, which is less than what was measured in the current experiment, can lead to a considerable difference in tibiofemoral contact variables [37].

According to the study of Torzilli et al., the small difference between the intact and dissected knees at varus and external rotational and posterior translational mechanical loads could 
be attributed to the popliteofibular ligament [10]. They also reported a limited static mechanical resistance of the popliteal tendon in varus, more particularly at $30^{\circ}$, where the maximum varus difference occurred in the current study. In the study of Griffith et al., with loading conditions similar to the loads applied in the current study, a reduced internal and valgus rotational stiffness at low flexion was reported, in the knees with the OPL dissected [15].

In the subject-specific FE models of the three cadaveric knees used in this study, modeling only the main structures of the knee joint could not acceptably predict the pre-dissected knee laxity in the experiment. Adding APL, OPL, ALL, MCap, and LCap as spring elements with adjusted stiffness in FE models, however, improved the replication of the pre-dissected knee behavior.

The main limitation of this study was the low number of specimens, which makes it impossible to draw general conclusions from the results, except demonstration of the interspecimen variation in the effect of peripheral soft tissue on joint kinematics. A second limitation is the fact that the current in vitro experiments were performed statically, while the in vivo dynamics may be different specifically, as it has been proposed that the popliteal tendon mostly acts dynamically to stabilize the knee joint [38]. A larger tensile force could be more representative for the physiological patellar muscle force and might influence the stability of the joint. However, it was previously shown that proportional larger quadriceps force would result in similar patellofemoral laxity patterns as the quadriceps loads applied in the current study [39]. In the FE models, the stiffness of the additional structures were manually adjusted, where following a more robust optimization routine could improve the stiffness estimation further. Nonetheless, even with the manual adjustment, the FE models revealed an improvement in the laxity prediction of pre-dissected knees.

\section{Conclusions}

Our findings indicated that in lax knees, ignoring the posterior capsule and peripheral soft tissues in computational models of the knee joint may lead to higher anterior translations and limited alterations in valgus rotations at $90^{\circ}$ during unloaded flexion. Excluding these structures from the models may also result in an increase in posterior translational and valgus and internal rotational laxities when the knee is flexed. Consequently, if the simulation contains any flexion under posterior, internal, and valgus loads or unloaded deep flexion, it is strongly recommended to incorporate the posterior capsule and peripheral tissue representations, as for instance incorporated in this study.

Acknowledgments This study was a part of BioMechTools project (ERC-2012-ADG LS7) and received funding from the European Research Council under the European Union's Seventh Framework Program (FP/2007-2013)/ERC Grant Agreement n. 323091.

\section{Compliance with ethical standards}

Conflict of interest The authors declare that they have no conflict of interest.

Open Access This article is distributed under the terms of the Creative Commons Attribution 4.0 International License (http:// creativecommons.org/licenses/by/4.0/), which permits unrestricted use, distribution, and reproduction in any medium, provided you give appropriate credit to the original author(s) and the source, provide a link to the Creative Commons license, and indicate if changes were made.

\section{References}

1. Taylor M, Prendergast PJ (2015) Four decades of finite element analysis of orthopaedic devices: where are we now and what are the opportunities? J Biomech 48(5):767-778

2. Kazemi M, Dabiri Y and Li LP 2013 Recent advances in computational mechanics of the human knee joint. Comput Math Methods Med vol 2013:1-7

3. Moglo KE, Shirazi-Adl A (2003) On the coupling between anterior and posterior cruciate ligaments, and knee joint response under anterior femoral drawer in flexion: a finite element study. Clin Biomech 18(8):751-759

4. Moeinzadehj H, Erkan A (1983) Response of a two-dimensional dynamic model of the human knee to the externally. J Biomed Eng 5:281-291

5. Shin CS, Chaudhari AM, Andriacchi TP (2009) The effect of isolated valgus moments on ACL strain during single-leg landing: a simulation study. J Biomech 42(3):280-285

6. Baldwin MA, Clary CW, Fitzpatrick CK, Deacy JS, Maletsky LP, Rullkoetter PJ (2012) Dynamic finite element knee simulation for evaluation of knee replacement mechanics. J Biomech 45(3):474-483

7. Brantigan OC, Voshell AF (1941) The mechanics of the ligaments and menisci of the knee joint. J Bone Jt Surg 23:44-66

8. Geiger D, Chang EY, Pathria MN, Chung CB (2014) Posterolateral and posteromedial corner injuries of the knee. Magn Reson Imaging Clin N Am 22(4):581-599

9. LaPrade RF (2007) The anatomy of the medial part of the knee. J. Bone Jt. Surg 89(9):2000

10. Torzilli PA, Maynard MJ, Warren RF (1995) The role of the popliteofibular stability of the human knee ligament in study *. Am J Sport Med 24(1):19-27

11. Shahane SA, Ibbotson C, Strachan R, Bickerstaff DR (1999) The popliteofibular ligament. J Bone Jt Surg 81(4):636-642

12. Michael J, Deng X, Wickiewicz TL, Warren RF (1996) "The Popliteofibular Ligament Rediscovery of a Key Element in Posterolateral Stability,” Am. J. Sports Med., 24(3):311-316

13. Sugita T, Amis AA (2001) Anatomic and biomechanical study of the lateral collateral and popliteofibular ligaments. Am J Sports Med 29(4):466-472

14. Mootanah R, Imhauser CW, Reisse F, Carpanen D, Walker RW, Koff MF, Lenhoff MW, Rozbruch R, Fragomen AT, Kirane YM, Rozbruch SR, Dewan Z, Cheah K, Dowell JK, Hillstrom HJ (2014) Development and verification of a computational model of the knee joint for the evaluation of surgical treatments for osteoarthritis. Comput Methods Biomech Biomed Eng 17(13. Taylor \& Francis):1502-1517

15. Griffith CJ, Wijdicks CA, Laprade RF, Armitage BM, Johansen S, Engebretsen L (2010) The American Journal of Sports Medicine force measurements on the posterior oblique ligament and superficial medial collateral ligament proximal and distal. Am J Sports Med 37(1):140-148 
16. Rachmat HH, Janssen D, Verkerke GJ, Diercks RL, Verdonschot N (2015) Material properties of the human posterior knee capsule. Biomed Mater Eng 25(2):177-187

17. Rood A, Hannink G, Lenting A, Groenen K, Koeter S, Verdonschot N, van Kampen A (2015) Patellofemoral pressure changes after static and dynamic medial patellofemoral ligament reconstructions. Am J Sports Med 43(10):2538-2544

18. Rachmat HH, Janssen D, Verkerke GJ, Diercks RL, Verdonschot N (2016) In-situ mechanical behavior and slackness of the anterior cruciate ligament at multiple knee flexion angles. Med Eng Phys 38(3):209-215

19. Luites JWH, Wymenga AB, Blankevoort L, Kooloos JMG, Verdonschot N (2012) Computer-assisted anatomically placed double-bundle ACL reconstruction: an in vitro experiment with different tension angles for the AM and the PL graft. Med Eng Phys 34(8):1031-1036

20. Farahmand F, Senavongse W, Amis AA (1998) Quantitative study of the quadriceps muscles and trochlear groove geometry related to instability of the patellofemoral joint. J Orthop Res 16(1):136-143

21. Farahmand F, Tahmasbi MN, Amis A (2004) The contribution of the medial retinaculum and quadriceps muscles to patellar lateral stability — an in-vitro study. Knee 11(2):89-94

22. Miranda DL, Rainbow MJ, Leventhal EL, Crisco JJ, Fleming BC (2010) Automatic determination of anatomical coordinate systems for three-dimensional bone models of the isolated human knee. $\mathrm{J}$ Biomchanics 43(8):1623-1626

23. Zevenbergen WJ (2012) Improved anatomical coordinate system of the distal femur based on 3D bone geometry \& evaluation of the inter- and intra-observer variability of the knee ligament attachment sites. University of Twente, Enschede

24. Grood WJ, Suntay ES (1983) A joint coordinate system for the clinical description of three-dimensional motions applications to the knee. J Biomech Eng 105(2):136-144

25. Gollehon DL, Torzilli PA, Warren RF (1987) The role of the posterolateral and cruciate ligaments in the stability of the human knee. A biomechanical study. J Bone Joint Surg Am 69(2):233-242

26. Seering WP, Piziali RL, Nagel DA, Schurman DJ (1980) The function of the primary ligaments of the knee in varus-valgus and axial rotation. J Biomech 13(9):785-794

27. Markolf KL, Mensch JS, Amstutz HC (1976) Stiffness and laxity of the knee - the contributions of the supporting structures. J. Bone Joint Surg 58(5):583-594

28. van Dommelen JAW, Minary Jollandan M, Ivarsson BJ, Millington SA, Raut M, Kerrigan JR, Crandall JR, Diduch DR (2006) Nonlinear viscoelastic behavior of human knee ligaments subjected to complex loading histories. Ann Biomed Eng 34(6):1008-1018

29. Naghibi Beidokhti H, Janssen D, Van De Groes S, Hazrati J, Van Den Boogaard T, Verdonschot N (2017) The influence of ligament modelling strategies on the predictive capability of finite element models of the human knee joint. J. Biomech. https://doi.org/10. 1016/j.jbiomech.2017.08.030

30. Laprade RF, Tso A, Wentorf F (2004) Force measurements on the fibular collateral ligament, popliteofibular ligament, and popliteus tendon to applied loads. Am J Sports Med 32(7):1695-1701

31. Laprade RF, Morgan P, Wentorf F, Johansen S, Engebretsen L (2007) The anatomy of the posterior aspect of the knee: an anatomic study. J Bone Joint Surg 89(4):758-764

32. Ishigooka H, Sugihara T, Shimizu K, Aoki H, Kazuaki H (2004) Anatomical study of the popliteofibular ligament and surrounding structures. J Orthop Sci 9(1):51-58
33. Werner FW, Ayers DC, Maletsky LP, Rullkoetter PJ (2005) The effect of valgus/varus malalignment on load distribution in total knee replacements. J Biomech 38(2):349-355

34. Engin AE, Korde MS (1974) Biomechanics of normal and abnormal knee joint. J Biomech 7(4):325-328

35. Heegaard JH, Leyvraz PF, Hovey CB (2001) A computer model to simulate patellar biomechanics following total knee replacement: the effects of femoral component alignment. Clin Biomech 16(5): 415-423

36. Marouane H, Shirazi-Adl A, Hashemi J (2015) Quantification of the role of tibial posterior slope in knee joint mechanics and ACL force in simulated gait. J Biomech 48(10):1899-1905

37. Yao J, Salo AD, Lee J, Lerner AL (2008) Sensitivity of tibiomenisco-femoral joint contact behavior to variations in knee kinematics. J Biomech 41(2):390-398

38. Guha AR, Gorgees KA, Walker DI (2003) Popliteus tendon rupture: a case report and review of the literature. Br J Sports Med 37: $358-360$

39. Farahmand F, Tahmasbi MN, Amis AA (1998) Lateral forcedisplacement behaviour of the human patella and its variation with knee flexion - a biomechanical study in vitro. J Biomech 31(12): $1147-1152$

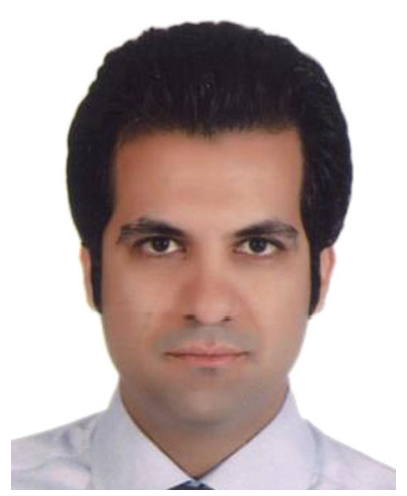

Hamid Naghibi Beidokhti, M.Sc., is a last-year-PhD student in biomedical science at Orthopedic Research Lab in Radboud University Medical Center, The Netherlands. He received his M.Sc. in Mechanical Engineering from Sharif University of Technology and B.Sc. in Mechanical Engineering from Ferdowsi University of Mashad, Iran. His research focus is computational modeling of human knee joint, more particularly finite element simulations, as a biomechanical diagnostic, pre-planning, and outcome tool to improve musculoskeletal surgery.

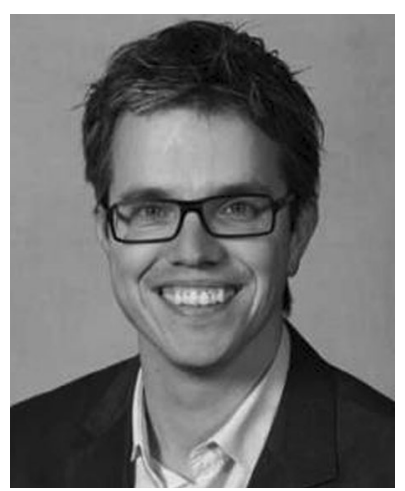

Dennis Janssen , Ph.D., is an assistant professor at Radboud University Medical Center, The Netherlands. He completed his Ph.D. in Medical Science in Radboud University Nijmegen, M.Sc. in Biomechanical Engineering in University of Twente, and B.Sc. in Mechanical Engineering in Fontys University of Applied Science, The Netherlands. His field of research mostly concerns the computational and experimental biomechanical analysis of issues related to orthopedic surgery (total joint arthroplasty, implant fixation, etc.). 


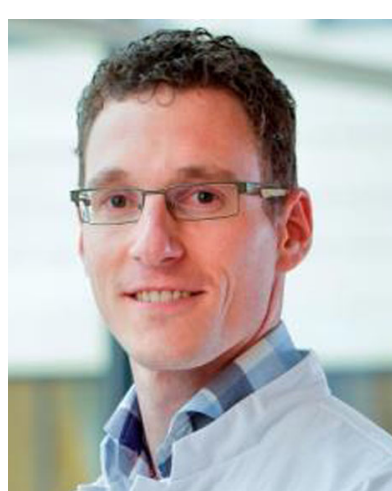

Sebastiaan van de Groes , M.D., is an orthopedic surgeon in Radboud University Medical Center, The Netherlands. His field of focus includes knee and revision surgery, patellofemoral instability, and traumatology.

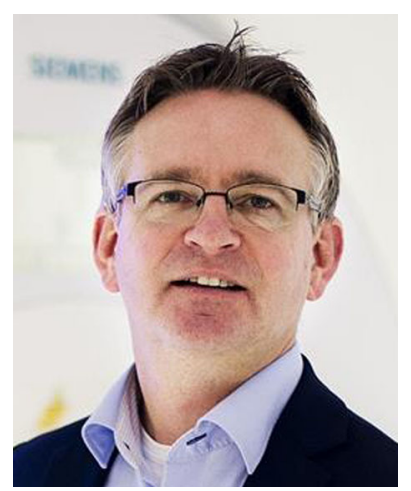

Nico Verdonschot, Ph.D., is professor of Biomechanics in Radboud University Medical Center and University of Twente, The Netherlands. He received his Ph.D. (Medical Science) from Radboud University Medical Center and M.Sc. (Mechanical Engineering) from Twente University, The Netherlands. His research interests are focused on orthopedic-biomechanical problems of the lower extremity, utilizing computer modeling techniques in combination with cadaveric testing, animal research, and clinical studies. 